This item was submitted to Loughborough's Research Repository by the author.

Items in Figshare are protected by copyright, with all rights reserved, unless otherwise indicated.

\title{
A novel compact fractal UWB antenna with triple reconfigurable notch reject bands applications
}

\section{PLEASE CITE THE PUBLISHED VERSION}

https://doi.org/10.1016/j.aeue.2019.01.018

\section{PUBLISHER}

(C) Elsevier

VERSION

AM (Accepted Manuscript)

\section{PUBLISHER STATEMENT}

This paper was accepted for publication in the journal AEU - International Journal of Electronics and Communications and the definitive published version is available at https://doi.org/10.1016/j.aeue.2019.01.018.

\section{LICENCE}

CC BY-NC-ND 4.0

\section{REPOSITORY RECORD}

Nazeri, Amir H., Abolfazl Falahati, and Robert Edwards. 2019. "A Novel Compact Fractal UWB Antenna with Triple Reconfigurable Notch Reject Bands Applications". Loughborough University. https://hdl.handle.net/2134/36694. 


\section{Accepted Manuscript}

Regular paper

A Novel Compact Fractal UWB Antenna with Triple Reconfigurable Notch Reject Bands Applications

Amir H. Nazeri, A. Falahati, R.M. Edwards

PII:

S1434-8411(18)31470-5

DOI: https://doi.org/10.1016/j.aeue.2019.01.018

Reference: AEUE 52650

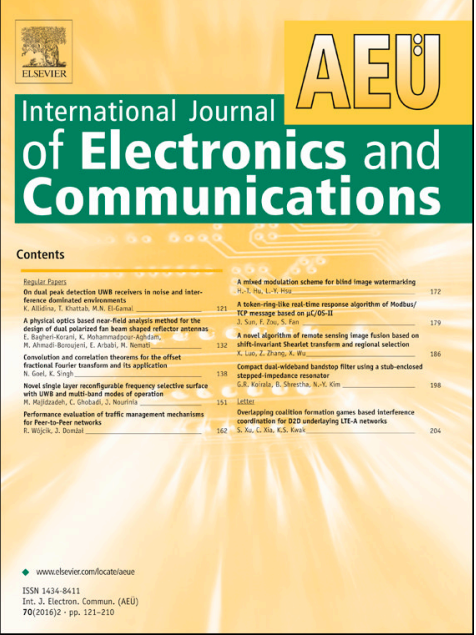

To appear in: $\quad$ International Journal of Electronics and Communications

Received Date: $\quad$ 4 June 2018

Accepted Date: $\quad 17$ January 2019

Please cite this article as: A.H. Nazeri, A. Falahati, R.M. Edwards, A Novel Compact Fractal UWB Antenna with Triple Reconfigurable Notch Reject Bands Applications, International Journal of Electronics and Communications (2019), doi: https://doi.org/10.1016/j.aeue.2019.01.018

This is a PDF file of an unedited manuscript that has been accepted for publication. As a service to our customers we are providing this early version of the manuscript. The manuscript will undergo copyediting, typesetting, and review of the resulting proof before it is published in its final form. Please note that during the production process errors may be discovered which could affect the content, and all legal disclaimers that apply to the journal pertain. 


\title{
A Novel Compact Fractal UWB Antenna with Triple Reconfigurable Notch Reject Bands Applications
}

\author{
Amir H. Nazeri ${ }^{1}$ A. Falahati ${ }^{2} \quad$ R.M. Edwards ${ }^{3}$ \\ ${ }^{1}$ School of Electrical and Computer Engineering, Texas Tech University, USA \\ ${ }^{2}$ School of Electrical Engineering, Iran University of Science and Technology, Tehran \\ ${ }^{3}$ Department of Electrical Engineering, Loughborough University, UK \\ afalahati@iust.ac.ir
}

\begin{abstract}
A compact, circular UWB fractal antenna with triple reconfigurable notch rejection bands is proposed. It rejects the crowded frequency bands WiMAX, WLAN and $\mathrm{X}$ band interferences produced in UWB communication systems. The proposed fractal structure consists of a basic circular patch with circular fractal iterations. By employing this new structure of fractals, the overall size of antenna is reduced $53 \%$ to $21 \times 25 \mathrm{~mm}$, in comparison with traditional circular monopole antenna. The implemented antenna operates at 3.1-10 GHz. Reconfigurability is realized by designing slots and split ring resonators in desired frequencies with the attached PIN diodes. WLAN band rejection was realized by creating a pair of optimized L-shaped slots in the ground plane. By etching a split ring resonator and a U-shaped slot, $\mathrm{X}$ and WiMAX bands were also rejected. Furthermore, by attaching diodes to aforementioned slots and designating the diodes on/off, different bands can be included or rejected. In time domain, the antenna properties are evaluated by a figure of merit called fidelity factor. Finally, the antenna properties are measured in anechoic chamber and the results agrees with simulation findings.
\end{abstract}

\section{Introduction}

The allocation of 3.1 to $10.6 \mathrm{GHz}$ band by FCC as Ultra-Wide Band (UWB) application is now well established for both UWB systems and antenna designers. Studying some antenna designers attempts [1,2], by designing different slots such as $\mathrm{T}$ and $\mathrm{L}$ slots as well as tuning stubs, the $80 \%$ band width is achieved with a less-than-satisfactory gain. In [3], electromagnetic band gap structures (EBG) and defected ground are used to attain a wide band scenario. Another method studied in [4], employs multilayer structures and places gaps between patch and ground plane to provide a $66 \%$ bandwidth with average gain of $3 \mathrm{~dB}$. It must be emphasized that, most of the considered methods have limitations in fabrication and antenna specs enhancement. Another possible method for designing an UWB antenna is the use of fractal structures. Fractal structures are usually utilized because of their suitable radiation patterns and UWB bandwidth, which are a result of fractals self-similarity and space-filling properties [5, 6]. Fractal antennas have compact sizes, impedance compatibility, high directivity, and can be designed for 
multiband and broadband applications. Some of the most popular fractal geometries are Minknowski fractals, Serpienski fractals, recursive trees, Hilbert curves, and Koch structures [7, 8]. Within such a wide band that UWB is situated, many different systems with their appropriate bands exist that could well produce frequency interferences. The three major narrow band systems, Worldwide Interoperability for Microwave Access (WiMAX) in $3.3-3.8 \mathrm{GHz}$ band, Wireless Local Area Network (WLAN) in 5.15-5.85GHz band, and X-band (military satellite communication) in $8-10 \mathrm{GHz}$ band, not mentioning many different RFID bands that could exist within UWB bands regions can cause interference over UWB antennas. To overcome such interferences, UWB antennas with notches in the mentioned frequencies are required. In [9-19], several UWB antennas with notch band characteristics are presented that employs EBG and defected structures for rejecting application. Moreover, as WLAN is more prone to interference in comparison with WiMAX and X-band, so single-band/dual-band selectivity for WiMAX and Xband can be very useful [20-23]. Indeed, employment of antennas with configurable notch band selectivity can be desirable. But this method makes antenna bigger in size and more complex in design. In [24] unwanted band is rejected by placing a T-type slot on the patch microstrip. In [25], a pair of parasitic strips are placed beside the feed line to reject WLAN band. Other means of unwanted frequency band rejection, studied in the literature, include placing half wavelength and quarter wavelength resonators as well as cutting away $\mathrm{H}$-shaped slots from the radiating patch [26, 27]. In [28], a desired band-notch antenna is achieved by etching a narrowband dual resonance fractal binary tree into the radiating element of UWB antenna. In this paper, a new UWB circular fractal reconfigurable antenna with band rejection capability is proposed. Two L-shaped slots are used besides feed line to reject WLAN band. For WiMAX and X band rejections, a simple U-shaped slot and a C-shaped split ring resonator are employed, respectively. In order to enable reject band selectivity, PIN diodes are embedded in the middle of the defined slots appropriately, so that by switching diodes, unwanted frequency bands can be filtered out. The switches cause changes in the current path and antenna electrical length. In fact, by placing switches on the slots, the electrical length and antenna notch frequencies can be altered $[29,30]$. In $3 \mathrm{GHz}$ and higher bands, the antenna simulated and measured S11 is below $-10 \mathrm{~dB}$. The substrate is FR-4 with $\varepsilon_{r}=4.4$ and loss tangent of 0.025 . The antenna dimensions are $21 \times 25 \mathrm{~mm} 2$. Design and fabrication of this fractal antenna is much simpler and cheaper in comparison with many other fractal counterparts.

\section{Antenna design procedure}

\subsection{Design of Fractal Circular Patch Antenna (FCPA)}

In this section, a new Fractal Circular Patch Antenna (FCPA) design process is explained in details. The original antenna is a circular patch set by smaller circular patches (CPs) with fixed distances from center point of the original CP. In figure 1, the constitutive parameters of fractal antenna is demonstrated. $r_{1}$ represents basic patch radii and $r_{2}, r_{3, \ldots}$ are the radius of other iterations. The $a_{n}$ acts as sequential coefficients between sequential $r_{n}$ $\left(r_{n}=a_{n} \times r_{n-1}\right)$. This figure also shows that, in each iteration two new $\mathrm{CP}$ enter the antenna design process. The 
angle between two adjacent $\mathrm{CP}$ at the center from previous iteration $\mathrm{CP}$ is shown by $\gamma_{n}$. Another factor that makes crucial effect on antenna size and operation is $D_{n}$. This is formulated as:

$D_{n}=\frac{p_{n}}{r_{n}+r_{n-1}}=\frac{r_{n}+r_{n-1}-d_{n}}{r_{n}+r_{n-1}}=1-\frac{d_{n}}{r_{n}+r_{n-1}}=1-\frac{1}{1+a_{n}} \cdot \frac{d_{n}}{r_{n-1}}$

In fact, $D_{n}$ stands for how much overlapping two sequential CPs may have.

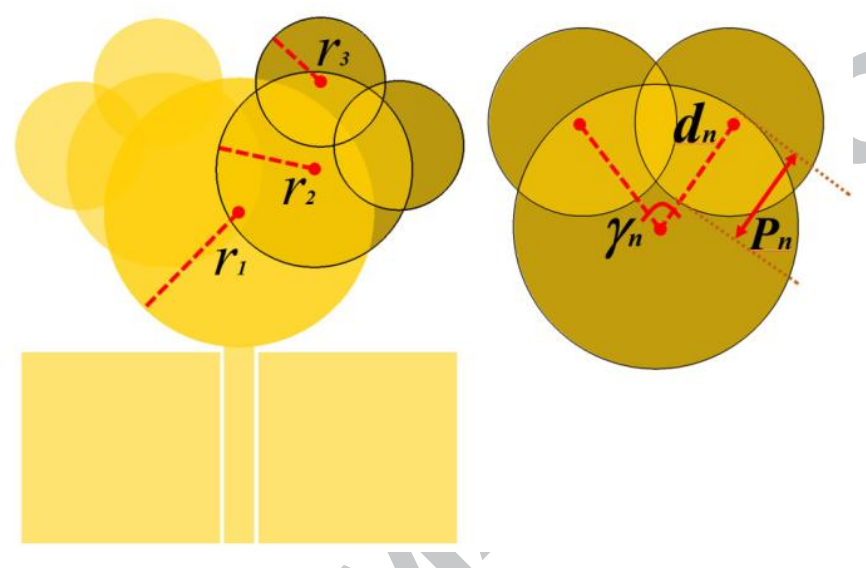

Fig. 1 The general sketch of FCPA with the antenna depiction at second iterations.

By changing any parameters, the antenna size and bandwidth will alter. Thus, the best results must be chosen, i.e., high bandwidth and minimum size. This could be achieved by various optimization methods. In this paper the FCPA is fulfilled at second iterations.

\subsubsection{A practical problem}

In figure $2, W_{g}$ and $L_{g}$ are the substrate length and width at $21 \mathrm{~mm}$ and $25 \mathrm{~mm}$, respectively. $h_{s}$ is the distance between antenna and ground plane. $L_{w}=1.5 \mathrm{~mm}$ that denotes the feed line width. $L_{W}$ and the distance between feed line and ground plane are chosen such that the feed line is matched with $50 \Omega$ impedance. The substrate which is used in simulations is FR-4 with $\varepsilon_{r}=4.4$ and loss tangent of 0.025 To define the constitutive parameters $a_{n}, r_{n}$, $\gamma_{n}$ and $D_{n}$ of the proposed FCPA (Fig. 1), by which the antenna operates in desired bandwidth of 3-12 GHz, a genetic optimization algorithm is employed. To make the optimization algorithm faster and easier, it is assumed that the parameters value of $D_{1}$ and $D_{2}$ are the same and $\gamma_{n}=\gamma_{1}=\gamma_{2}$. And after optimization process, the following parameter are found as; $\mathrm{r}_{1}=6.6 \mathrm{~mm}, \mathrm{a}_{2}=0.8, \mathrm{a}_{3}=0.6, \mathrm{D}_{1}=0.6, \mathrm{D}_{2}=0.6, \gamma_{n}=65^{\circ}$.

The result of analysis of $h_{s}$ parameter is shown in figure 2. To find the efficiency of this method, the FCPA is compared with simple CP. The relation between dimensions and resonant frequency in circular patch antenna at initial stage are as reference [31]. According to [31], the radius of a simple circular patch for resonating at $3 \mathrm{GHz}$ is 
$14 \mathrm{~mm}$ and by simulation, the overall size of 30x36 for simple CP. Considering same bandwidth for FCPA and simple CP by applying the proposed fractal, the miniaturization of $\% 53$ is achieved as shown by figure 3 . In figure 5, the original antenna and iterations one and two are shown. All the three antenna dimensions are considered the same, i.e., taking into account fractal iterations effect. The radius of the initial antenna (Fig. 5(a)) is 9mm, and the radius of basic antenna in first and second iterations (Fig. 5(b) - Fig. 5(c)) are 8mm and $6.6 \mathrm{~mm}$ respectively. The results of the return loss for different antenna iterations can be observed in figure 6 .

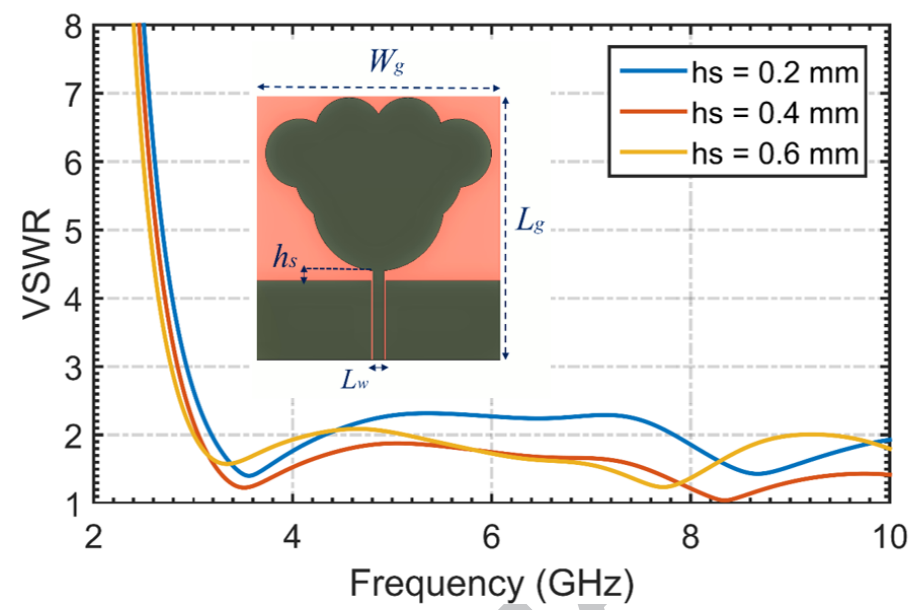

Fig. 2 Proposed FCPA configuration with $h_{s}$ parameter demonstration, VSWR optimization in terms of $h_{s}=0.2,0.4,0.6$

As demonstrated in figure 2, changes in $h_{s}$ (the distance between patch and ground plane), have considerable effect on impedance matching and return loss.

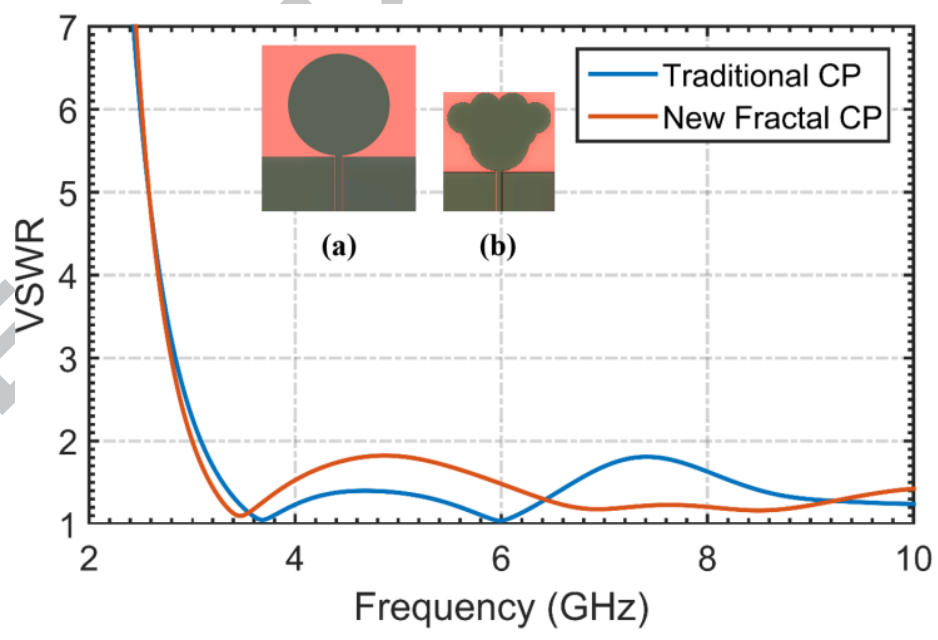

Fig. 3 Comparison between return loss of (a)-Traditional circular patch(CP), (b)-Second iteration of the proposed fractal antenna 


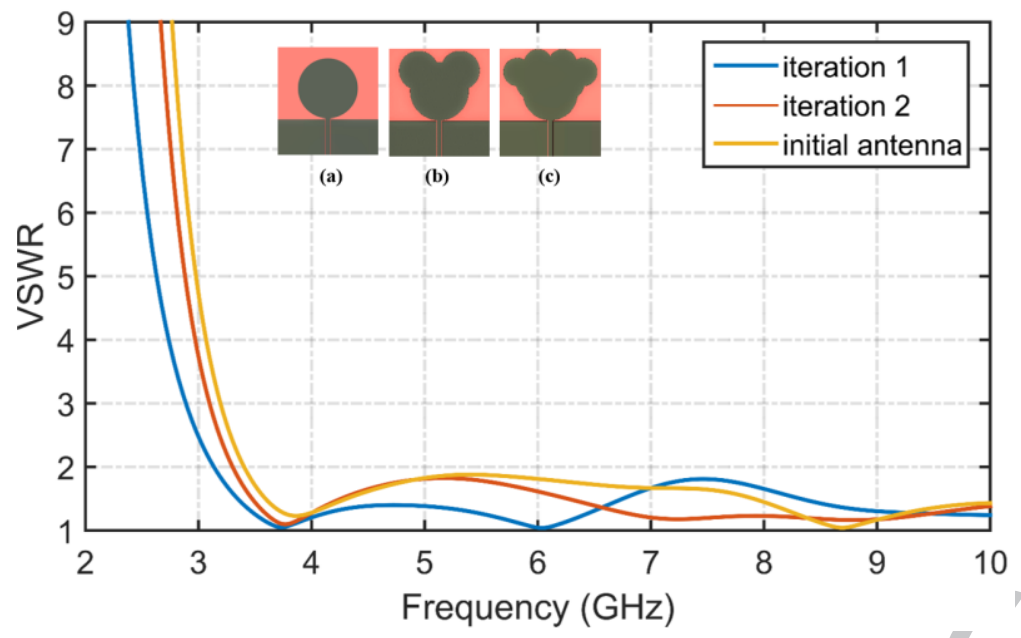

Fig. 4 (a) Geometry of the simple traditional CP. (b) Iteration-1 of the fractals. (c) Iteration-2 of the fractals, shown in figure 1

As it can be seen in figure 4, the bandwidth in iteration 2 is increased to $3.05-10 \mathrm{GHz}$ that, in respect to initial antenna of 3.6-10GHz, a significant increase can be observed. It can be observed that, by making the antenna a fractal kind, the impedance matching in the lower frequencies has improved. The fractal shaped boundary increases the electrical length and thereby magnetic current path of antenna.

\subsection{Notch Band Rejection Implementation}

By etching two modified L-shaped slots beside the feed line, a notch in WLAN frequency band is implemented. Also, by designing of a C-type slot and a split ring resonator, WiMAX and X bands are rejected too. Approximate length of each slot is calculated by:

$L_{n o t c h}=\frac{c}{2 f_{\text {notch }} \sqrt{\varepsilon_{\text {eff }}}}=\frac{\lambda_{g}}{2}$

where L, c, and $\varepsilon_{\text {eff }}$ denote slot length, speed of light in free space, and effective dielectric constant, respectively [32]. Because of the approximations involved in (2) and variations in conditions of the environment, in general, total band rejection is not achieved. To overcome this problem, an optimization algorithm to calculate appropriate slot length is proposed. Flowchart of the algorithm is shown in figure 7.The embedded slots over the FCPA is shown in figure 8. 


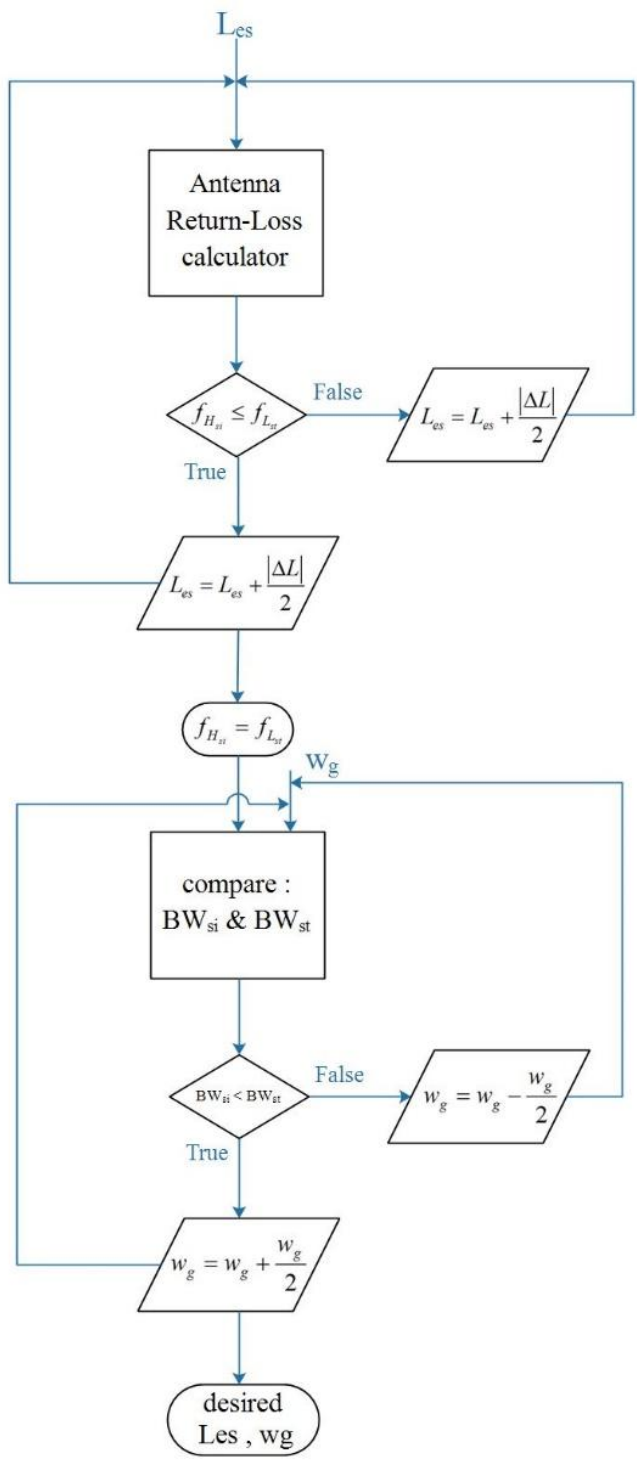

Fig.5 Flowchart for the optimized design algorithm

The parameters given in figure 5 are as follows:

$\mathrm{L}_{\text {eff }}=\mathrm{L}_{\text {effective }}$

$\mathrm{L}_{\mathrm{es}}=\mathrm{L}_{\text {estimated }}$

$|\Delta \mathrm{L}|=\left|\mathrm{L}_{\mathrm{es}}-\mathrm{L}_{\mathrm{eff}}\right|$

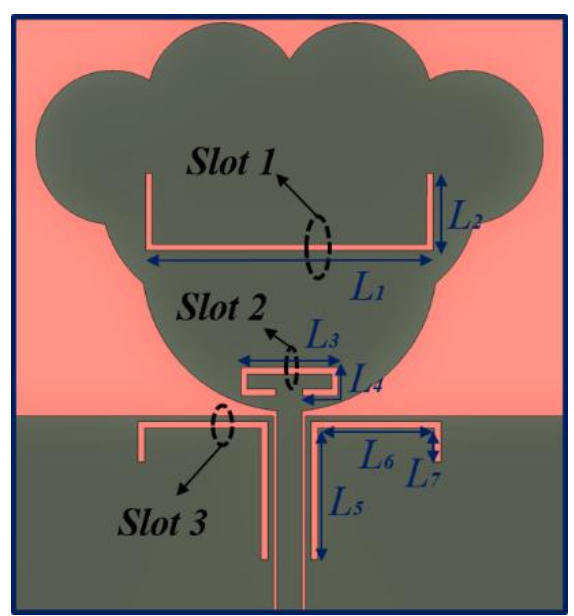

Fig. 6 The embedded slots shape to reject the mentioned bands 
So, the purposes of the slots in figure 6 are slot one to reject the WiMAX band and slots 2 and 3 to reject X-band and WLAN, respectively. Considering (2) and figure 6, the slot sizes can be calculated as,

$$
\begin{gathered}
L_{\text {slot } 1}=L 1+2 * L 2 \approx \lambda_{g} / 2 \\
L_{\text {slot } 2}=L 3+2 * L 4 \approx \lambda_{g} / 2 \\
L_{\text {slot } 3}=L 5+L 6+L 7 \approx \lambda_{g} / 2
\end{gathered}
$$

Implementing the flowchart of figure 5, the optimized values of the slot sizes are, $L 1=15, L 2=5.6, L 3=4.6, L 4=3.4, L 5=7.2, L 6=7.5, L 7=3.4$

As shown in figure 7, by attaching two PIN diodes on slot 1 and slot 2, they become reconfigurable. So, by biasing the diodes and switching them on or off, each band can be rejected at will. For this purpose, two Infineon BAR50-02v PIN diodes were chosen. Some experimental researches [33-36] are carried out employed PIN diodes as means of antenna reconfiguration that present technical biasing tips. In the biasing circuit, a 100pF capacitor is used to isolate DC and RF signals. Diodes are biased with a DC power supply (VCC) to a common node of the each capacitor and diode. A series inductor-resistor with values of $3 \mathrm{nH}$ and $50 \Omega$ is used in DC supply path in order to prevent RF signal from damaging DC supply.

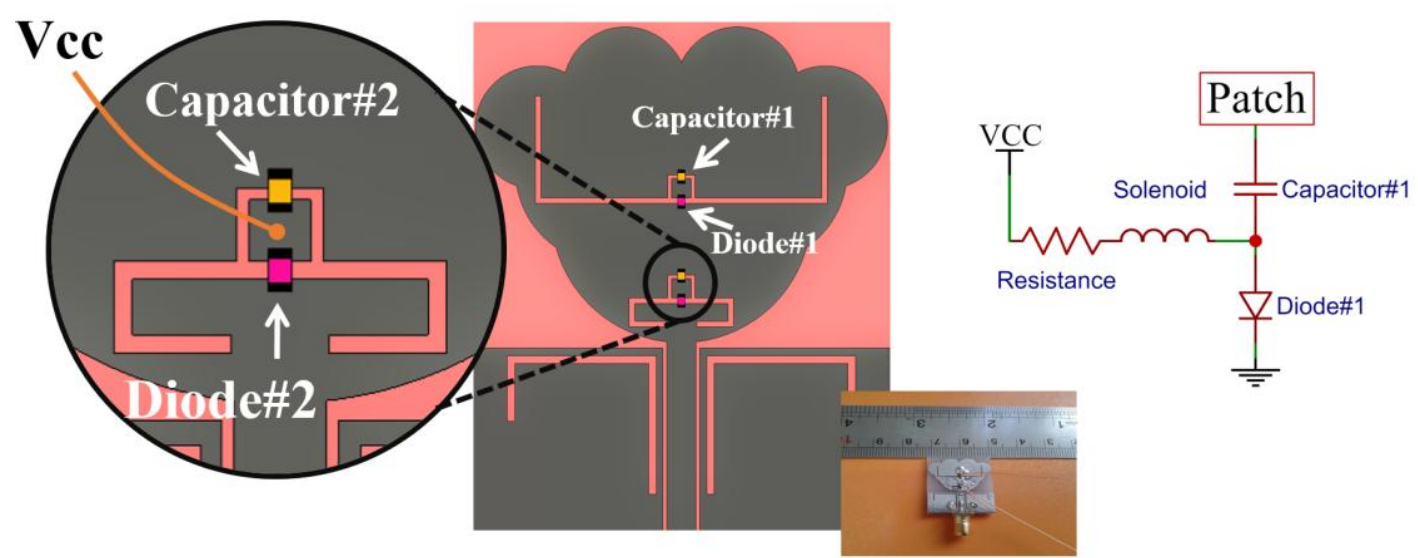

Fig. 7 Geometry parameter of the proposed reconfigurable fractal UWB antenna with PIN diode configuration and Fabricated antenna with DC biased diodes

\section{Simulation Results}

\subsection{Antenna Reconfigurability}

In figure 8, simulation and measurement results for S11 parameter of the reconfigurable circular fractal patch antenna is shown. Diodes D1 and D2 are placed on U-slots, so that by switching them on and off, WiMAX and X bands can be reconfigurably rejected. Measurement is performed using Agilent E5071C Vector Network Analyzer. 
It is observed that, good agreement exists between measurement and simulation results. VSWR graph shown in figure 8 for different band rejection configurations are described by 4 states as below:

(a)- state1, when both diodes are off, UWB antenna with triple notch band rejection is achieved.

(b)- state2, when Diode1 is switched off and Diode2 is switched on, the antenna rejects WiMAX and WLAN bands.

(c)- state3, when Diode1 is switched on and Diode2 is switched off, the antenna acts as a UWB antenna with WLAN and X-band rejection.

(d)- state4, when both diodes are switched on, antenna radiates in all UWB frequency range, except WLAN band. As demonstrated in figure 8, changes in switching state of the diodes provides reconfigurable notch band rejection.

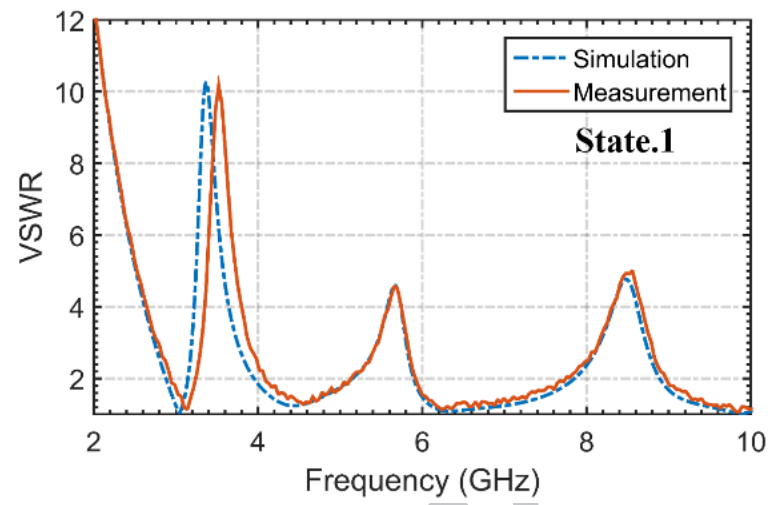

(a)

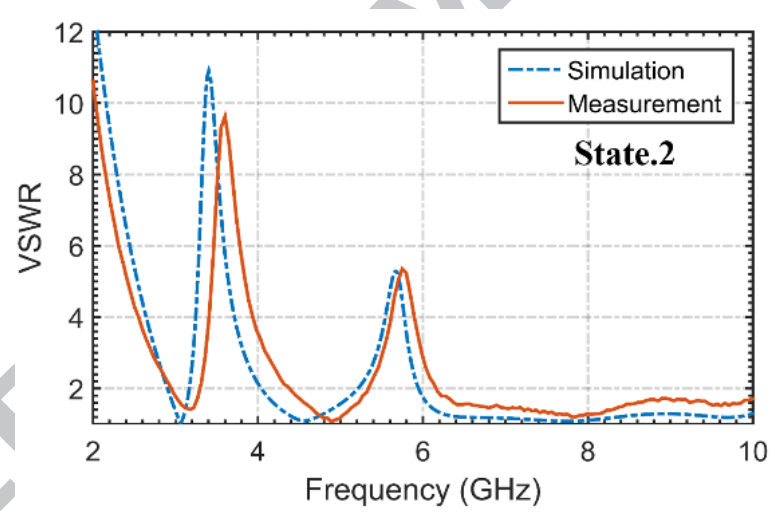

(b)

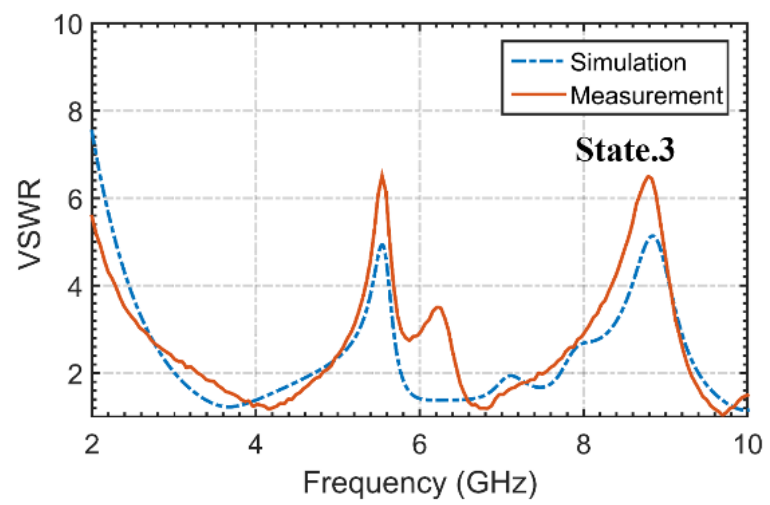

(c) 


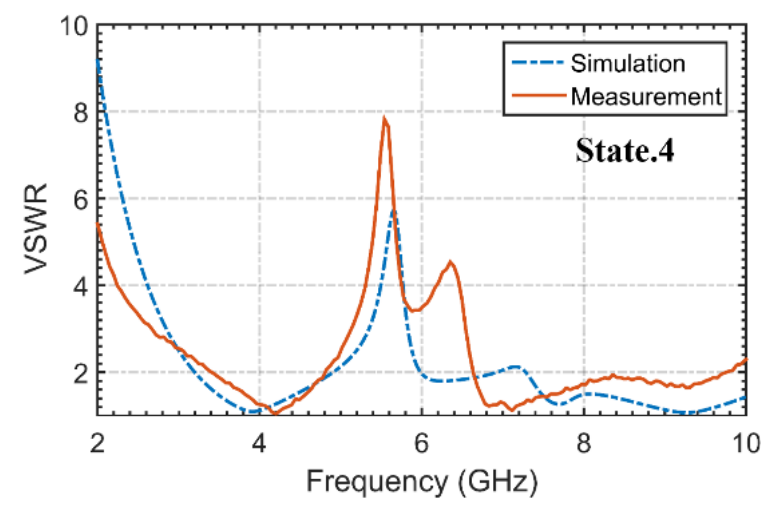

(d)

Fig 8. Simulation and measurement results for $S 11$

In figure 9, surface current density distribution in reject-band frequencies can be observed. In notch band frequencies, most of the current flows through edges of the slots which causes low gain and low radiation.

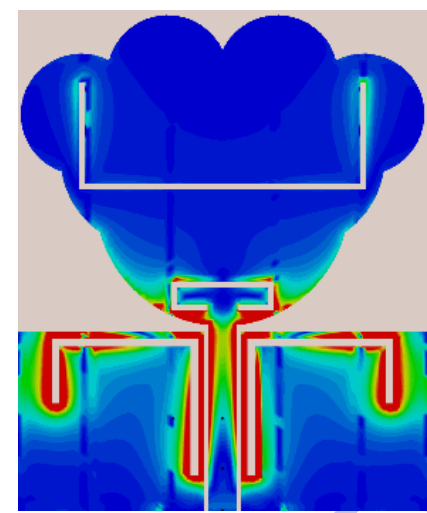

(a)

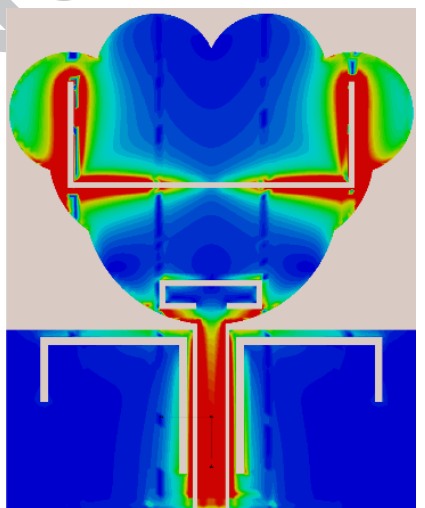

(b)

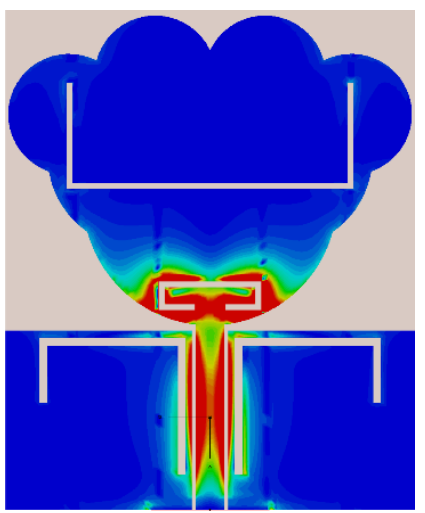

(c)

Fig.9 Surface current density distribution for (a). 3.6GHz (b). $5.6 \mathrm{GHz}$ (c) $9 \mathrm{GHz}$

The current flow, around the slot reveals that the direction of current in either edges of the slots are opposite each other. This creates destructive interference and makes the antenna non-radiating at $3.6 \mathrm{GHz}, 5.6 \mathrm{GHz}$ and $9 \mathrm{GHz}$. 


\subsection{Radiation Performance}

Measured and simulated radiation patterns of the proposed antenna in E-plane (yz-plane) and H-plane (xz-plane) at resonant frequency is depicted in figure 10. The measurements are carried out at the state1.

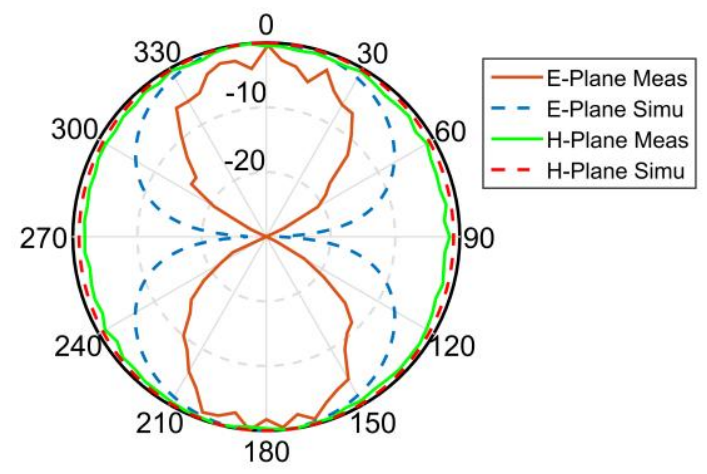

(a)

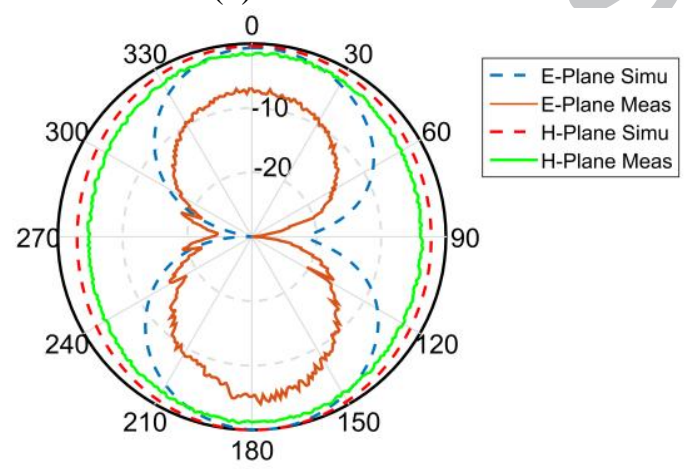

(b)

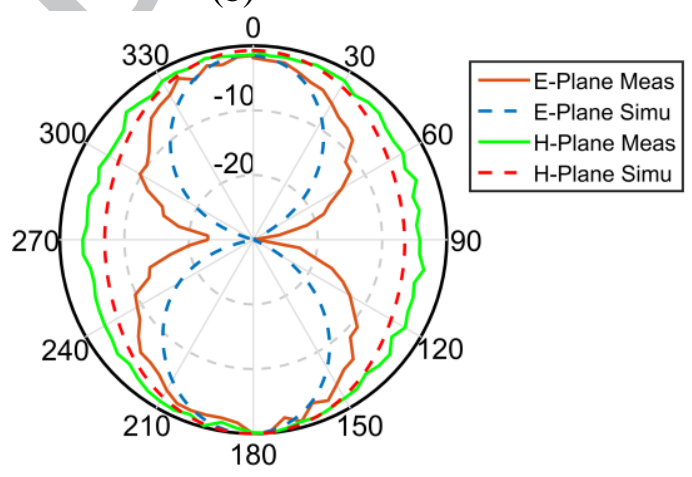

(c)

Fig.10 Measured and simulated E-plane and H-plane radiation patterns of the proposed antenna at resonant frequencies of (a) 4.3 $\mathrm{GHz},($ b) $6.7 \mathrm{GHz}$, and (c) $10 \mathrm{GHz}$

In figure 11, measured gain value of the proposed antenna in different frequency ranges is demonstrated. It can be seen that, the measured gain in notch frequencies is decreased to its lowest level. Also the results of antenna efficiency is depicted in figure 12 . 


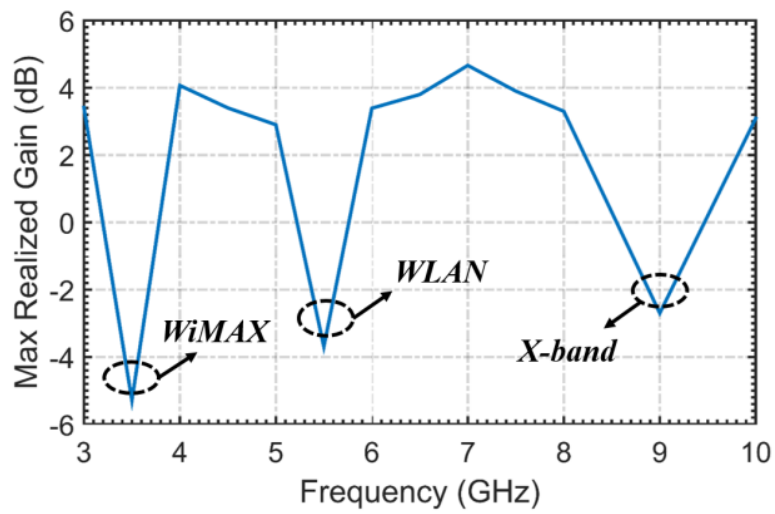

Fig.11 Measured gain value of the proposed UWB reconfigurable fractal antenna

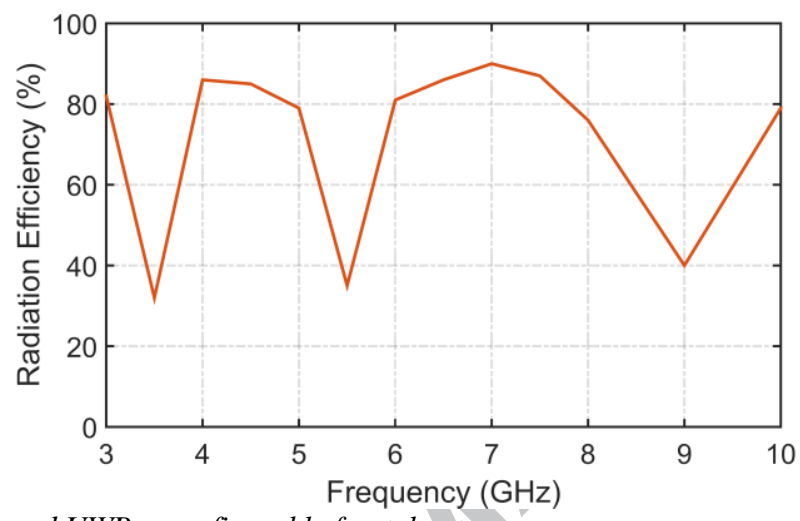

Fig.12 Radiation Efficiency proposed UWB reconfigurable fractal antenna

The proposed FCPA is presented in table 1 in comparison with some of the already published identical antennas.

Table 1. Comparison of the proposed FCPA with other recent UWB antennas

\begin{tabular}{|c|c|c|c|c|}
\hline Ref & BW & Size(mm) & Notches & $\begin{array}{c}\text { Switching } \\
\text { capability }\end{array}$ \\
\hline$[\mathbf{3 7 ]}$ & UWB & $34 \times 35.9$ & 2 & yes \\
\hline$[\mathbf{3 8}]$ & UWB & $24 \times 32$ & 2 & no \\
\hline$[\mathbf{3 9}]$ & UWB & $35 \times 35$ & 3 & no \\
\hline$[\mathbf{4 0}]$ & UWB & $30 \times 35$ & 3 & no \\
\hline$[\mathbf{2 1}]$ & UWB & $25 \times 28$ & 1 & no \\
\hline$[\mathbf{4 1}]$ & UWB & $27 \times 30.5$ & 3 & no \\
\hline$[\mathbf{4 2}]$ & UWB & $27 \times 32$ & 2 & yes \\
\hline$[\mathbf{4 3}]$ & UWB & $26.8 \times 38.7$ & 3 & yes \\
\hline$[\mathbf{4 4}]$ & UWB & $26 \times 30$ & 3 & no \\
\hline$[\mathbf{4 5}]$ & UWB & $27 \times 36$ & 4 & no \\
\hline$[\mathbf{4 6}]$ & UWB & $25 \times 25$ & 0 & no \\
\hline$[\mathbf{4 7}]$ & UWB & $50 \times 50$ & 3 & no \\
\hline$[\mathbf{1 8}]$ & UWB & $32 \times 24$ & 1 & no \\
\hline$[\mathbf{1 3}]$ & UWB & $32 \times 24$ & 2 & no \\
\hline$[\mathbf{1 7}]$ & UWB & $30 \times 32$ & 3 & yes \\
\hline $\begin{array}{c}\text { Proposed } \\
\text { antenna }\end{array}$ & UWB & $21 \times 25$ & 3 & yes \\
\hline & & & & \\
\hline
\end{tabular}

\subsection{Time-domain Analysis}

It is vital to analyze the UWB structures in time-domain. Signals transmitted by UWB structures are prone to amplitude, and phase distortion. In order to investigate this problem, the structure group delay must be calculated. If the group delay is less than or equal to $1 \mathrm{~ns}$, distortion caused by the system is negligible. In other words, 
transmitted and received signal must be almost the same. Hence, correlation between transmitted and received signal is expressed as fidelity factor which is given by:

$$
\rho=\max _{\tau}\left\{\left|\frac{\int S(t) R(t-\tau) d t}{\sqrt{\int S^{2}(t) d t} \sqrt{R^{2}(t) d t}}\right|\right\}
$$

Where $\tau, S(t)$ and $R(t)$ represent delay, source pulse, and received pulse, respectively. When correlation of two signals is 1 , the signals are basically the same and have no distortion. In order to investigate group delay in simulation, Gaussian modulated pulse with 3-12 GHz spectrum by CST software package is chosen, which fulfills the FCC indoor and outdoor power mask criteria. A virtual probe in antenna far field is employed, situated $70 \mathrm{~cm}$ away from the antenna, with angles of 0,45 and -45 degrees. For appropriate matching of the radiated pulse and the source pulse, fidelity factor must be above 0.71. [48, 49]

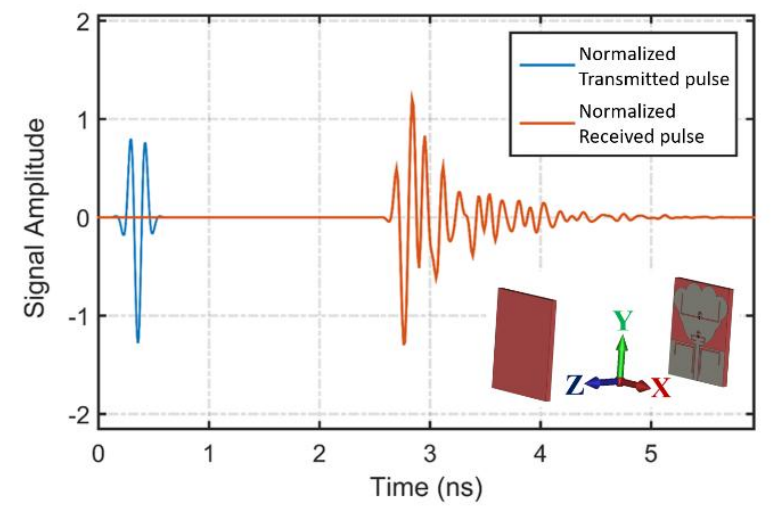

Fig.12 Normalized source and received signal at plane $z-y(\theta=0, \varphi=90)$. The investigation is carried out for state1

Table 2. Calculated fidelity factor for six different situations

\begin{tabular}{|l|c|c|c|}
\hline $\begin{array}{c}\text { Probe Positions } \\
\text { X-z plane }\end{array}$ & $\begin{array}{c}\text { Fidelity } \\
\text { Factor }\end{array}$ & $\begin{array}{c}\text { Probe Positions } \\
\text { z-y plane }\end{array}$ & $\begin{array}{c}\text { Fidelity } \\
\text { Factor }\end{array}$ \\
\hline$\theta$ & 0.745 & $\theta$ & 0.721 \\
\hline$\theta=0, \varphi=0$ & 0.832 & $\theta$ & 0.805 \\
\hline & 0.792 & $\theta$ & 0.796 \\
\hline
\end{tabular}

As shown in table 2, it can be observed that, present antenna causes little distortion and fulfills the requirements in time domain, as well as the frequency domain.

\section{Conclusions}

A compact UWB fractal antenna with triple reconfigurable notch rejection bands is implemented, to reject the crowded frequency bands WiMAX, WLAN and X band interferences produced in UWB communication systems. The proposed structure consists of a basic antenna with 2 circular fractal iterations. By employing this new structure 
of fractal, the overall size of antenna is reduced $\% 53$, to $21 \times 25$. This antenna size is smaller than many available

UWB antennas and has a suitable gain too. The designed antenna is also investigated in time domain to prove the employment of the antenna for UWB applications.

\section{References}

1. I. Latif, Saeed., Shafai, L.,Sharma, S.K.: 'Bandwidth Enhancement and Size Reduction of Microstrip Slot Antennas', IEEE Trans. Antennas Propag., 2005, vol. 53, no. 3, pp. 865-872

2. Sharma, S.K., Shafai, L., Jacob, N.: 'Investigations of wide band microstrip slot antenna', IEEE Trans. Antennas Propag., 2004, vol. 52 , no. 3 , pp. $865-872$

3. M.E. De Cos, Y. Álvarez, F. Las-Heras.: 'Enhancing patch antenna bandwidth by means of uniplanar EBG-AMC', Microwave and Optical Technology Lett, 2011, vol. 53, no. 6, 1372-1377

4. Lakrit, Soufian, Ammor, Hassan.: ' Design of Multilayer Microstrip Patch Antenna Using T-probe for UWB Communications', Journal of Engineering Technology., 2015 ,vol.3, pp. 19-24

5. Werner, D.H., Haupt, R.L., and Werner, P.L.: 'Fractal antenna engi- neering: The theory and design of fractal antenna arrays', IEEE Antennas Propag Mag., 1999, vol.41, pp. 37-58

6. Singhal, Sarthak, and A.K. Singh.: 'CPW-fed octagonal super-wideband fractal antenna with defected ground structure', IET Microwaves, Antennas \& Propagation. , 2016, 11.3, pp. 370-377

7. P. Baliarda, C. Puente, J. Romeu, R. Pous, and A. Cardama.: 'On the behavior of the Sierpinski multiband fractal antenna'. IEEE Trans. Antennas Propag., 1998, vol.46, no.4, pp. 517-524

8. P. Baliarda, C. Puente, J. Romeu, and A. Cardama.: 'The Koch monopole: A small fractal antenna'. IEEE Trans. Antennas Propag., 2000, .vol48, no.11, pp. 1773-1781

9. Gao, P., Xiong, L., Dai, J., S. He, and Zheng, Y.: 'Compact printed wide-slot UWB antenna with 3.5/5.5-GHz dual band-notched characteristics', IEEE Antennas Wirel. Propag. Lett. 2013, pp. 983-986

10. Abdollahvand M., Dadashzadeh, G., and Mostafa, D.: 'Compact dual band-notched printed monopole antenna for UWB application', IEEE Antennas Wireless Propag Lett., 2010, vol.9, pp. 1148-1151

11. Azim, R., Islam, M. T., and Mobashsher, A.T.: 'Dual band-notch UWB antenna with single tri-arm resonator', IEEE Antennas Wireless., 2014, pp. 670-673

12. Li, Y., Li, W., \& Yu, W. (2014). A CPW- fed circular slot UWB antenna with WLAN band and X- band filtering characteristics using hybrid resonators. Microwave and Optical Technology Letters, 56(4), 925-929.

13. Li, Y., Li, W., \& Mittra, R. (2014). Miniaturized CPW- FED UWB antenna with dual frequency rejection bands using stepped impedance stub and arc- shaped parasitic element. Microwave and Optical Technology Letters, 56(4), 783-787.

14. Li, Y., Li, W., \& Ye, Q. (2014). A compact circular slot UWB antenna with multimode reconfigurable band- notched characteristics using resonator and switch techniques. Microwave and Optical Technology Letters, 56(3), 570-574.

15. Li, Y., Li, W., \& Yu, W. (2013). A Compact Reconfigurable Antenna Using SIRs and Switches for Ultra-Wideband and MultiBand Wireless Communication Applications. Applied Computational Electromagnetics Society Journal, 28(5).

16. Li, Y., Li, W., \& Yu, W. (2012). A switchable UWB slot antenna using SIS-HSIR and SIS-SIR for multi-mode wireless communications applications. Applied Computational Electromagnetics Society Journal, 27(4).

17. Li, Y., Li, W., \& Ye, Q. (2013). A reconfigurable triple-notch-band antenna integrated with defected microstrip structure band-stop filter for ultra-wideband cognitive radio applications. International Journal of Antennas and Propagation, 2013.

18. Li, Y., \& Li, W. (2014). A circular slot antenna with wide tunable and reconfigurable frequency rejection characteristic using capacitance loaded split-ring resonator for UWB applications. Wireless personal communications, 78(1), 137-149.

19. Li, Y., Li, W., \& Ye, Q. (2013). A reconfigurable wide slot antenna integrated with sirs for UWB/multiband communication applications. Microwave and Optical Technology Letters, 55(1), 52-55.

20. Liang, J., Chiau, C.C., Chen, X., and Parini, C.G.: 'Study of a printed circular disc monopole antenna for UWB systems', IEEE Trans. Antennas Propag., 2005, vol.53, no.11, pp. 3500-3504

21. Eshtiaghi, R., Nourinia, J., and Ghobadi, C.: 'Electromagnetically coupled band-notched elliptical monopole antenna for UWB applications', IEEE Trans. Antennas Propag., 2010 vol. 58, no. 4, pp. 1397-1402 Propag Lett ., 2014, vol.13, pp.670-673

22. A. Valizade, C. Ghobadi, J. Nourinia, and M. Ojaroudi, A novel design of reconfigurable slot antenna with switchable band notch and multi-resonance functions for UWB applications, IEEE Antennas Wireless Propag. Lett, 2012, vol.11, pp. 1166-1169

23. Badamchi, B., Nourinia, J., Ghobadi, C., and Valizade, A., Shahmirzadi.: 'Design of compact reconfigurable ultra-wideband slot antenna with switchable single/dual band notch functions', IET Microwave Antennas Propag., 2014, vol.8, pp. 541-548

24. Moosazadeh, M., Abbosh, A. M., and Esmati, Z.: 'Design of compact planar ultra-wideband antenna with dual-notched bands using slotted square patch and pi-shaped conductor backed plane', IET Microwaves, Antennas and Propog., 2012, vol.6, no.3, pp. 290-294

25. Jiang, W., and Che, W.: 'A novel UWB antenna with dual notched bands for WiMAX and WLAN applications', IEEE Antennas and Wireless Propag. Lett, 2012, vol. 11, pp.293-296

26. Ghatak, R., Debnath, R., Poddar, D.R., and Mishra, R.K.: 'A CPW fed planar monopole band notched UWB antenna with embedded split ring resonators', Loughborough Antennas and Propagation Conference, 2009, pp.645-647

27. Zheng, Z. A., Chu, Q.X., and Tu, Z.H.: 'Compact band- rejected ultra-wideband slot antennas inserting with $\lambda / 2$ and , $\lambda / 4$ resonator,' IEEE Transactions on Antennas and Propag, 2014, vol.59, no.2 
28. Jahromi, M. Naghshvarian, Abolfazl Falahati, and R. M. Edwards.:

'Application of fractal binary tree slot to design and construct a dual band-notch CPW-ground-fed ultra-wide band antenna.' IET microwaves, antennas \& propag, 2011, vol.5, no.12, pp. $1424-1430$

29. Yang, S., Chunna, Z., Helen, P., Fathy, A., and Nair, V.: 'Frequency reconfigurable antennas for multi radio wireless platforms', IEEE Microwave Mag., 2009, Vol. 10, No. 1,pp. 66-83

30. Luis, De, J. R. and F. de Flaviis, 'A reconfigurable dual frequency switched beam antenna array and phase shifter using PIN Diodes', IEEE Antennas and Propagation Society International Symposium, 2009.

31. Balanis, Constantine A. Antenna theory: analysis and design. John Wiley \& Sons, 2016.

32. D.M. Pozar, Microwave engineering, 2nd ed., Wiley, New York, 1998.

33. Gong, L., Chan, K. Y., \& Ramer, R. (2013, April). A beam steering single-arm rectangular spiral antenna with large azimuth space coverage. In Wireless and Microwave Technology Conference (WAMICON), 2013 IEEE 14th Annual (pp. 1-4). IEEE.

34. Gong, L., Yang, Y., Chan, K. Y., \& Ramer, R. (2014). RHCP pattern- reconfigurable spiral antenna biased with two DC signals. Microwave and Optical Technology Letters, 56(7), 1636-1640.

35. Gong, L., Chan, K. Y., \& Ramer, R. (2013, July). A reconfigurable spiral antenna with wide beam coverage. In Antennas and Propagation Society International Symposium (APSURSI), 2013 IEEE (pp. 206-207). IEEE.

36. Gong, L., Ramer, R., \& Yuk, K. (2014). Beam steering spiral antenna reconfigured by PIN diodes. International Journal of Microwave and Wireless Technologies, 6(6), 619-627.

37. Tang, M. Chun, H. Wang, T. Deng, and R.W. Ziolkowski.: 'Compact planar ultrawideband antennas with continuously tunable, independent band-notched filters'. IEEE Transactions on Antennas and Propag, 2016 vol.64, no.8, pp. 3292-3301

38. Li, Yingsong, W. Li, and Q. Ye.: 'A reconfigurable wide slot antenna integrated with sirs for UWB/multiband communication applications'. Microwave and Optical Technology Lett, 2013, vol. 55, no. 1, pp. 52-55

39. Sarkar, Debdeep, K.V. Srivastava, and K. Saurav.: 'A compact microstrip-fed triple band-notched UWB monopole antenna'. IEEE Antennas and Wireless Propagation Lett, 2014, vol. 13, pp. 396-399

40. Liu, Ying, Z. Chen, and S. Gong.: 'Triple band-notched aperture UWB antenna using hollow-cross-loop resonator'. Electronics Letters, 2014 Vol. 50, No. 10, pp. 728-730

41. Cai, Y. Zhi, H.C. Yang, and L.Y. Cai.: 'Wideband monopole antenna with three band-notched characteristics, IEEE Antennas and Wireless Propagation Letters, 2014, Vol. 13, pp. 607-610

42. Srivastava, Gunjan, S. Dwari, and B.K. Kanaujia.: 'A compact UWB antenna with reconfigurable dual notch bands'. Microwave and Optical Technology Lett, 2015, Vol. 57, No.12, pp. 2737-2742

43. Nikolaou, Symeon.: 'UWB elliptical monopoles with a reconfigurable band notch using MEMS switches actuated without bias lines'., IEEE Transactions on Antennas and Propag., 2009, vol.57, no.8, pp. 2242-2251

44. Ajay Y, Agrawal S and Yadav R.P, (2017), SRR and S-shape slot loaded triple band notched UWB antenna, AEU-International Journal of Electronics and Communications, vol. 79 pp. 192-198.

45. Mewara H. S, Mahendra D. J, Shamar M and Deepwal K, (2018), A printed monopole ellipzoidal UWB antenna with four band rejection characteristics, AEU-International Journal of Electronics and Communications, Vol. 83, pp. 222-232.

46. Fallahi $\mathrm{H}$ and Atlasbaf Z, (2015), Bandwidth enhancement of a CPW-fed monopole antenna with small fractal elements, $A E U$ International Journal of Electronics and Communications, vol. 69, issue 2 pp. 590-595.

47. Zarrabi F. B, Mansouri Z, Gandiji N. P and Kushestani H, (2016), Triple-notch UWB monopole antenna with fractal Koch and Tshaped stub, AEU International Journal of Electronics and Communications, vol. 70, issue 1, pp.64-69.

48. Tzyh-Ghuang, M., and Jeng, S.K.: 'Planar miniature tapered-slot-fed annular slot antennas for ultrawide-band radios', IEEE Trans Antennas Propag., 2005, vol.53, pp.1194-1202

49. Chacko, B.P., Augustin, G., and Denidni, T.A.: 'uniplanar slot antenna for ultrawideband polarization-diversity applications', IEEE Antennas Wireless Propag. Lett., 2013, vol.12, pp.88-91 


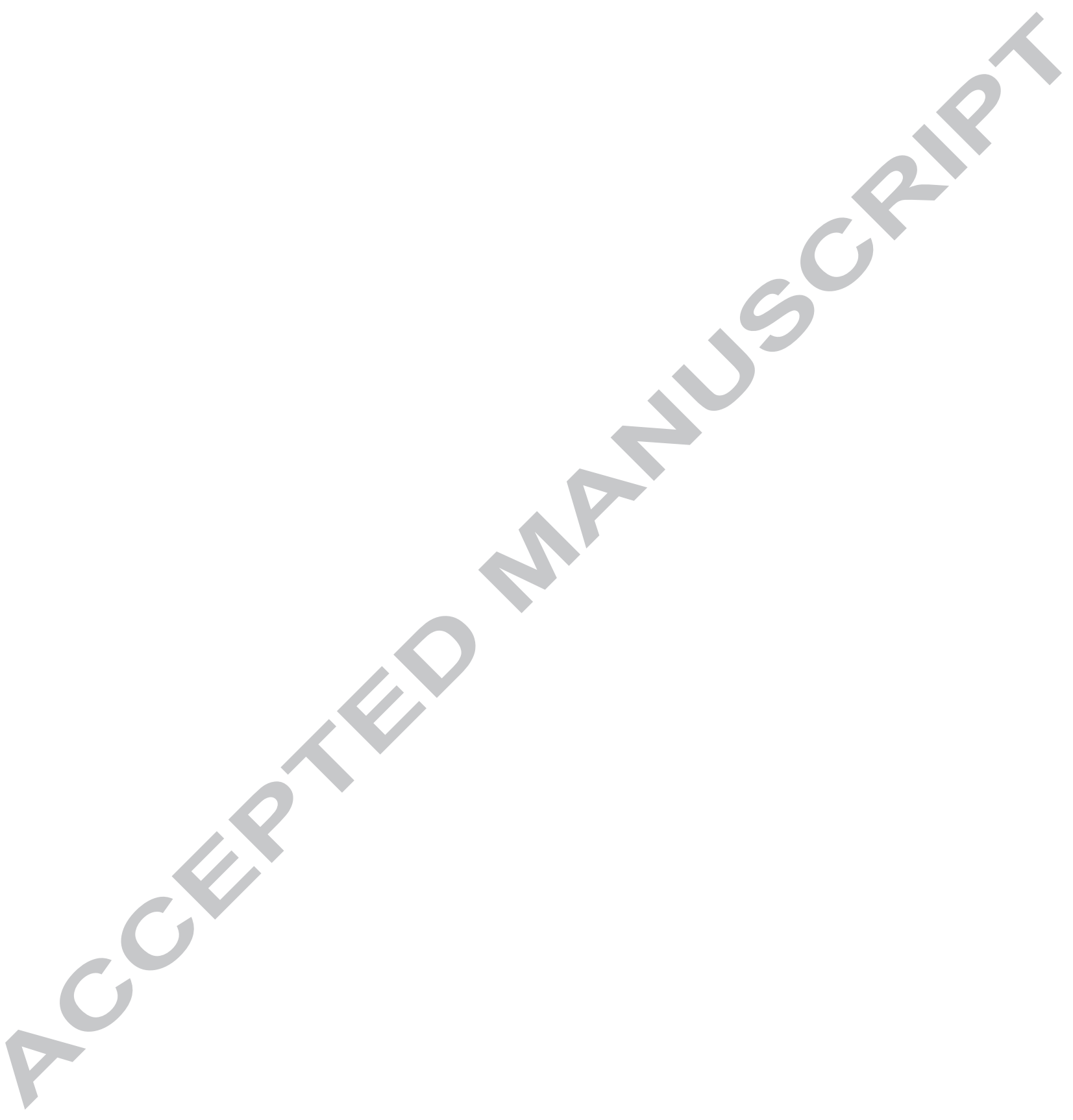

